\title{
Barriers to a Mediterranean diet in a Northern European population
}

\author{
S. E. Moore ${ }^{1}$, C. T. McEvoy ${ }^{1}$, L. Prior ${ }^{1}$, J. A. Lawton ${ }^{2}$, C. C. Patterson ${ }^{1}$, F. Kee ${ }^{1}$, M. Cupples ${ }^{1}$ \\ I. S. Young, ${ }^{1}$, S. J. Hunter ${ }^{3}$, D. McCance ${ }^{3}$, K. Appleton ${ }^{4}$, M. C. McKinley ${ }^{1}$ and J. V. Woodside ${ }^{1}$ \\ ${ }^{1}$ Centre for Public Health, Queen's University Belfast, Belfast, BT12 6BJ, UK, ${ }^{2}$ Public Health Sciences, University of \\ Edinburgh Medical School, Edinburgh, EH8 9AG, UK, ${ }^{3}$ Regional Centre for Endocrinology and Diabetes, Belfast \\ Health and Social Care Trust, Belfast, BT12 6BA, UK and ${ }^{4}$ Psychology Research Centre, Bournemouth University, \\ Bournemouth, BH12 5BB, UK
}

There is strong evidence linking consumption of the Mediterranean diet (MD) to a reduced risk of CVD ${ }^{(1)}$ and type II diabetes ${ }^{(2)}$, however there is uncertainty about whether non-Mediterranean regions will adopt this dietary pattern. A number of general barriers to dietary change are well documented in the literature ${ }^{(3-6)}$, but there is limited information on the specific barriers that may exist in relation to adoption of a MD by Northern European populations. This research aimed to investigate attitudes towards following a MD in individuals at high CVD risk in a Northern European population.

Focus groups $(n=12)$ were held with the target group and explored awareness of a MD, attitudes towards the key components of a MD and barriers to dietary change towards a MD. Discussions were audio-recorded, transcribed verbatim and data was analysed thematically. Nvivo software was used to manage the coded data.

Sixty-seven high CVD risk adults (60\% female, mean age 64 y) took part. Participants were aware of the MD, but knowledge of its composition was limited. Several barriers to consumption of a MD were identified, most of which were similar to barriers associated with general healthy eating, such as cost, availability, eating habits, lack of knowledge, lack of cooking skills and taste. However, further barriers specific to following a MD were identified, including food specific barriers, culture, climate and negative perceptions of the body image of those from the Mediterranean region.

\begin{tabular}{|c|c|}
\hline \multicolumn{2}{|c|}{ MD specific barriers } \\
\hline Red meat & $\begin{array}{l}\text { "Northern Ireland, I think, has a tradition of eating a lot of } \\
\text { red meat" }\end{array}$ \\
\hline Sweet foods & "I think we all have a sweet tooth, don't we?" \\
\hline Processed foods & $\begin{array}{l}\text { "I, just out of curiosity, watch people when I'm shopping, and } \\
\text { the amount of people that fill their trolleys out of the frozen } \\
\text { section with ready meals and pizzas and all that sort of stuff" }\end{array}$ \\
\hline Olive oil & $\begin{array}{l}\text { "I don't mind cooking in the olive oil and rapeseed oil but } \\
\text { don't ask me to pour it over pasta. I just wouldn't eat it" }\end{array}$ \\
\hline Nuts & "I don't buy them because I know they're fattening" \\
\hline Culture & $\begin{array}{l}\text { "But it's not natural to our way here in Northern Ireland toeat } \\
\text { that way" }\end{array}$ \\
\hline Climate & $\begin{array}{l}\text { "To me, it's not a diet that's sort of seems suited to our, whenI } \\
\text { say our way of life I mean our climate here really" }\end{array}$ \\
\hline Perceptionof & "But the thing that gets me is when you see films or if you'rein \\
\hline $\begin{array}{l}\text { Mediterranean } \\
\text { populations }\end{array}$ & the Mediterranean area, older people are quite fat" \\
\hline
\end{tabular}

This research indicates that although there was good awareness of the term MD in this Northern European sample at high risk of CVD, knowledge of the specific composition of a MD was limited. In addition to the usual barriers to dietary change, a number of barriers specific to a MD were identified. Interventions to encourage adoption of a MD in non-Mediterranean populations will need to ensure appropriate education and support is provided to address these knowledge gaps and barriers.

1. Estruch R, Ros E, Salas-Salvadó J et al. (2013) N Engl J Med, 368, 1279-1290.

2. Salas-Salvadó J, Bull M, Babio N et al. (2011) Diabetes Care, 34, 14-19.

3. Macdiarmid JI, Loe J, Kyle J et al. (2013) Appetite, 71, 411-419.

4. Pridgeon A \& Whitehead K (2013) J Hum Nutr Diet, 26, 85-95.

5. Gough B \& Connor MT (2006) Soc Sci Med, 62, 387-395.

6. de Almeida MD, Grace P, Afonso C et al. (2001) J Nutr Health Aging, 5, 217-219. 